\title{
Los dolores que nos quedan son las libertades que nos faltan
}

$\mathrm{A}$ ún resuenan estas palabras de los estudiantes reformistas. Hoy trabajamos y reclamamos por ese proyecto educativo inconcluso Compartimos en esta Editorial la Declaración III Conferencia Regional de Educación Superior para América Latina y el Caribe del 14 de junio en Córdoba, Argentina, a 100 años de la Reforma Universitaria.

"Mujeres y hombres de nuestra América, los vertiginosos cambios que se producen en la región y en el mundo en crisis nos convocan a luchar por un cambio radical por una sociedad más justa, democrática, igualitaria y sustentable".

Hace un siglo, los estudiantes reformistas proclamaron que "los dolores que nos quedan son las libertades que nos faltan" y no podemos olvidarlo, porque aún quedan y son muchos, porque aún no se apagan en la región la pobreza, la desigualdad, la marginación, la injusticia y la violencia social.

Los universitarios de hoy, como los de hace un siglo, nos pronunciamos a favor de la ciencia desde el humanismo y la tecnología con justicia, por el bien común y los derechos para todas y todos.

La III Conferencia Regional de Educación Superior de América Latina y el Caribe refrenda los acuerdos alcanzados en las Declaraciones de la Reunión de la Habana (Cuba) de 1996, la Conferencia Mundial de Educación
Superior de París (Francia) de 1998 y de la Conferencia Regional de Educación Superior celebrada en Cartagena de Indias (Colombia) en 2008 y reafirma el postulado de la Educación Superior como un bien público social, un derecho humano y universal, y un deber de los Estados. Estos principios se fundan en la convicción profunda de que el acceso, el uso y la democratización del conocimiento es un bien social, colectivo y estratégico, esencial para poder garantizar los derechos humanos básicos e imprescindibles para el buen vivir de nuestros pueblos, la construcción de una ciudadanía plena, la emancipación social y la integración regional solidaria latinoamericana y caribeña.

Reivindicamos la autonomía que permite a la universidad ejercer su papel crítico y propositivo frente a la sociedad sin que existan límites impuestos por los gobiernos de turno, creencias religiosas, el mercado o intereses particulares. La defensa de la autonomía universitaria es una responsabilidad ineludible y de gran actualidad en América Latina y el Caribe y es, al mismo tiempo, una defensa del compromiso social de la universidad.

La educación, la ciencia, la tecnología y las artes deben ser así un medio para la libertad y la igualdad, garantizándolas sin distinción social, de género, etnia, religión ni edad.

Pensar que las tecnologías y las ciencias resolverán los problemas acuciantes de la hu- 
manidad es importante pero no suficiente. El diálogo de saberes para ser universal ha de ser plural e igualitario, para posibilitar el diálogo de las culturas.

Las diferencias económicas, tecnológicas y sociales entre el norte y el sur, y las brechas internas entre los Estados no han desaparecido sino que han aumentado. El sistema internacional promueve el libre intercambio de mercancías, pero aplica excluyentes regulaciones migratorias. La alta migración de la población latinoamericana y caribeña muestra otra cara de la falta de oportunidades y la desigualdad que afecta, sobre todo, a las poblaciones más jóvenes. La desigualdad de género se manifiesta en la brecha salarial, la discriminación en el mercado laboral y en el acceso a cargos de decisión en el Estado o en las empresas. Las mujeres de poblaciones originarias y afrodescendientes son las que muestran los peores indicadores de pobreza y marginación. La ciencia, las artes y la tecnología deben constituirse en pilares de una cooperación para el desarrollo equitativo y solidario de la región, basadas en procesos de consolidación de un bloque económicamente independiente y políticamente soberano.

Las débiles regulaciones de la oferta extranjera han profundizado los procesos de transnacionalización y la visión mercantilizada de la educación superior, impidiendo, cuando no cercenando, en muchos casos, el efectivo derecho social a la educación. Es fundamental revertir esta tendencia e instamos a los Estados de América Latina y el Caribe a establecer rigurosos sistemas de regulación de la educación superior y de otros niveles del sistema educativo. La educación no es una mercancía. Por ello, solicitamos a nuestros Estados nacionales a no suscribir tratados bilaterales o multilaterales de libre comercio que impliquen concebir la educación como un servicio lucrativo, o alienten formas de mercantilización en cualquier nivel del sistema educativo, así como también a incrementar los recursos destinados a la educación, la ciencia y la tecnología.

Frente a las presiones por hacer de la educación superior una actividad lucrativa es imprescindible que los Estados asuman el compromiso irrenunciable de regular y evaluar a las instituciones y carreras, de gestión pública y privada, cualquiera sea la modalidad, para hacer efectivo el acceso universal, la perma- nencia y el egreso de la Educación Superior, atendiendo a una formación de calidad con inclusión y pertinencia local y regional.

De manera similar al año 1918, actualmente "la rebeldía estalla" en América Latina y el Caribe, y en un mundo donde el sistema financiero internacional concentra a las minorías poderosas y empuja a las grandes mayorías a los márgenes de la exclusión, la precariedad social y laboral.

A pesar de los enormes logros que se han alcanzado en el desarrollo de los conocimientos, la investigación y los saberes de las universidades y de los pueblos, un sector importante de la población latinoamericana, caribeña y mundial se encuentra sin acceso a los derechos sociales básicos, al empleo, a la salud, al agua potable o a la educación. En pleno siglo XXI, millones de niños, jóvenes, adultos y ancianos, están excluidos del actual progreso social, cultural, económico y tecnológico. Aún más, la desigualdad regional y mundial es tan pronunciada, que en muchas situaciones y contextos existen comunidades que no tienen acceso a la educación superior, porque esta aún sigue siendo un privilegio y no un derecho, como anhelaron los jóvenes en 1918.

En el Centenario de la Reforma, no somos ajenos al sufrimiento humano ni al mandato de la historia. No podemos seguir indiferentes al devenir del orden colectivo, a la lucha por la verdad heroica y al anhelo trascendente de la libertad humana. La Educación Superior debe constituirse desde los liderazgos locales, estatales, nacionales e internacionales, tal y como ahora están aquí representados plenamente.

Desde estos posicionamientos, será posible llevar a cabo una nueva e histórica transformación desde el compromiso y la responsabilidad social, para garantizar el pleno ejercicio al derecho a la Educación Superior pública gratuita $\mathrm{y}$ de amplio acceso.

En consonancia con el cuarto Objetivo de Desarrollo Sostenible (ODS) de la Agenda de Desarrollo adoptada por la UNESCO (2030), instamos a los Estados a promover una vigorosa política de ampliación de la oferta de Educación Superior, la revisión en profundidad de los procedimientos de acceso al sistema, la generación de políticas de acción afirmativas - con base en género, etnia, clase y capacidades diferentes- para lograr el acceso universal, la permanencia y la titulación. 
En este contexto, los sistemas de educación superior deben pintarse de muchos colores, reconociendo la interculturalidad de nuestros países y comunidades, para que sea un medio de igualación y de ascenso social y no un ámbito de reproducción de privilegios. No podemos callarnos frente a las carencias y los dolores del hombre y de la mujer, como sostuvo Mario Benedetti con vehemencia, "hay pocas cosas tan ensordecedoras como el silencio".

Hace un siglo, los estudiantes Reformistas denunciaron con firmeza que en una Córdoba y en un mundo injusto y tiránico, las universidades se habían convertido en el "fiel reflejo de estas sociedades decadentes que se empeñan en ofrecer el triste espectáculo de una inmovilidad senil". Ha pasado el tiempo y ese mensaje cargado de futuro nos interpela y nos atraviesa como una flecha ética, para cuestionar nuestras prácticas. ¿Qué aportamos para la edificación de un orden justo, la igualdad social, la armonía entre las Naciones y la impostergable emancipación humana?; ¿Cómo contribuimos a la superación del atraso científico y tecnológico de las estructuras productivas?; ¿Cuál es nuestro aporte a la forja de la identidad de los pueblos, a la integridad humana, a la igualdad de género y al libre debate de las ideas para garantizar la fortaleza de nuestras culturas locales, nacionales y regionales?
Es por eso que creemos fehacientemente que nuestras instituciones deben comprometerse activamente con la transformación social, cultural, política, artística, económica y tecnológica que es hoy imperiosa e indispensable. Debemos educar a la dirigencia del mañana con conciencia social y con vocación de hermandad latinoamericana. Forjemos comunidades de trabajo donde el anhelo de aprender y la construcción dialógica y crítica del saber entre docentes y estudiantes sea la norma. Construyamos ambientes democráticos de aprendizaje, donde se desenvuelvan las manifestaciones vitales de la personalidad y se expresen sin límites las creaciones artísticas, científicas y tecnológicas.

La Educación Superior para construir debe ejercer su vocación cultural y ética con la más plena autonomía y libertad, contribuyendo a generar definiciones políticas y prácticas que influyan en los necesarios y anhelados cambios de nuestras comunidades. La Educación Superior debe ser la institución emblemática de la conciencia crítica nacional de nuestra América.

Las instituciones de Educación Superior están llamadas a ocupar un papel preponderante en la promoción y fortalecimiento de las democracias latinoamericanas, rechazando las dictaduras y atropellos a las libertades públicas, a los derechos humanos y a toda forma de

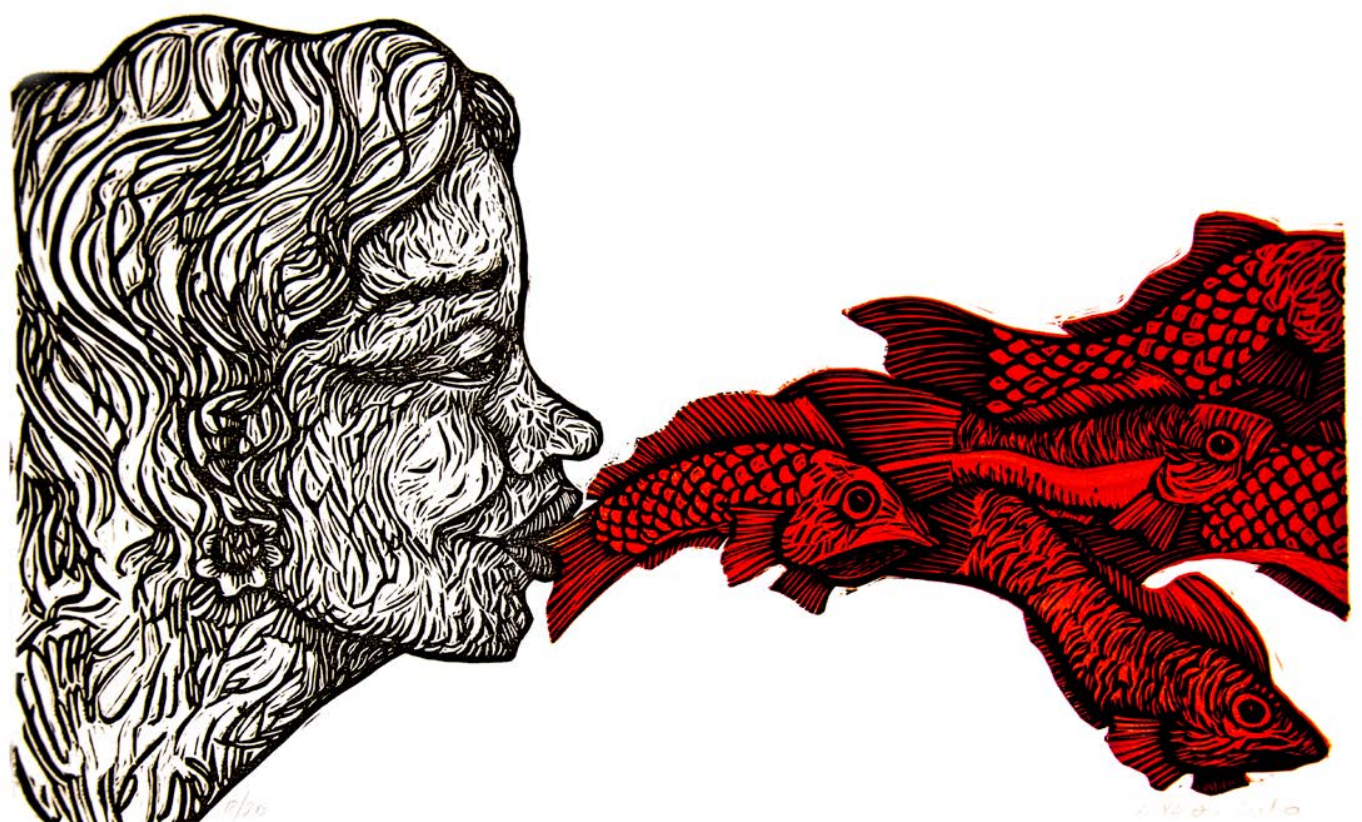

S/T, grabado. Dini Calderón 
autoritarismo en la región. Expresamos nuestra solidaridad con las juventudes de nuestra América y del mundo, cuyas vidas celebramos y reconocemos en sus luchas y anhelos, en nuestras propias aspiraciones a favor de la transformación social, política y cultural.

La tarea no es simple, pero es grande la causa e ilumina el resplandor de su verdad. Se trata, como profetizó el Manifiesto Liminar, de mantener alto el "sentido de un presagio glorioso, la virtud de un llamamiento a la lucha suprema por la libertad".
Mujeres y hombres del continente, miremos hacia el futuro y trabajemos sin pausa en la reforma educacional permanente, en el renacer de la cultura y de la vida de nuestras sociedades y pueblos".

Presentada en la asamblea de la III Conferencia Regional de Educación Superior celebrada en la Universidad Nacional de Córdoba, a los 14 días del mes de junio de 2018.

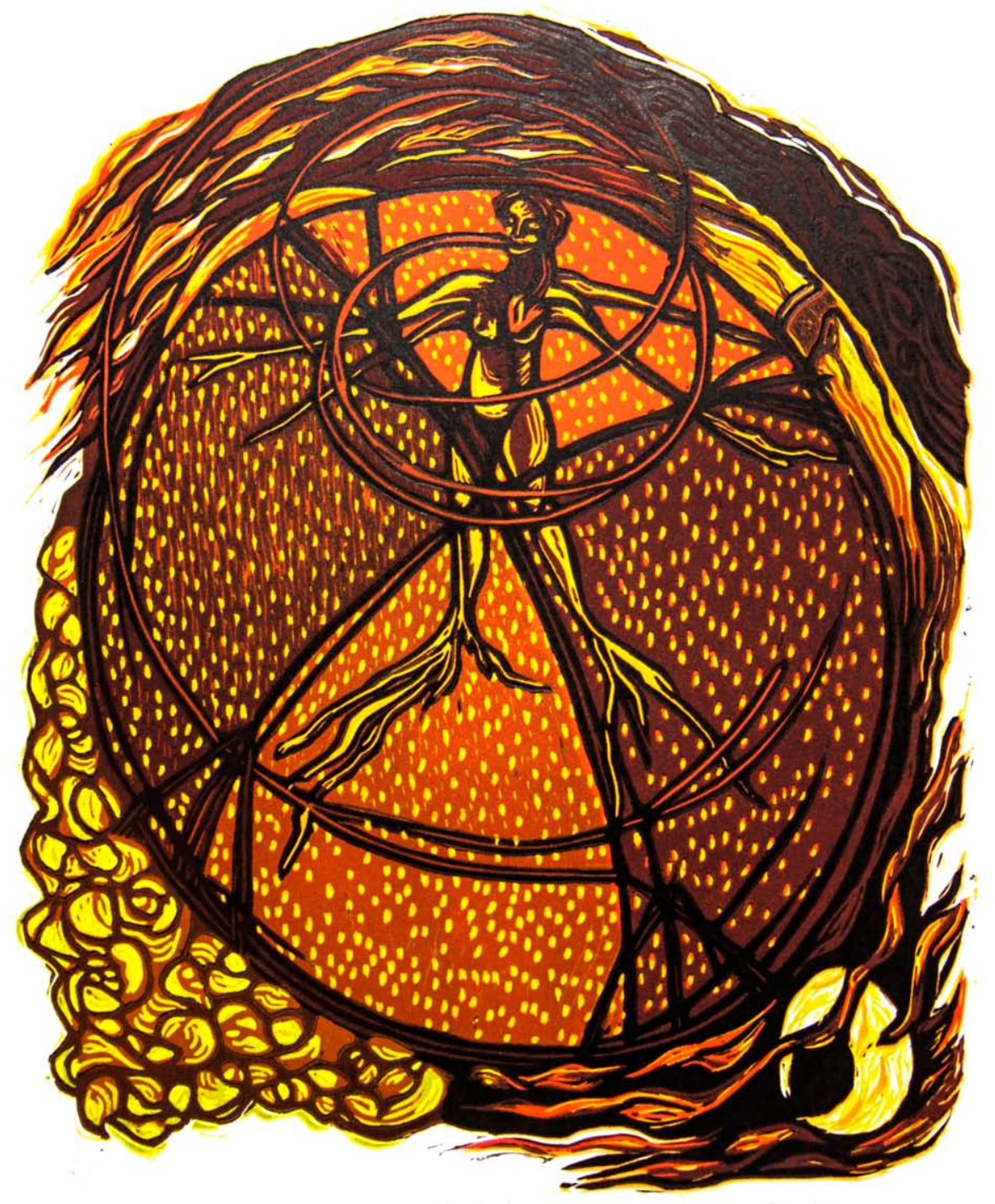

S/T, grabado. Dini Calderón 